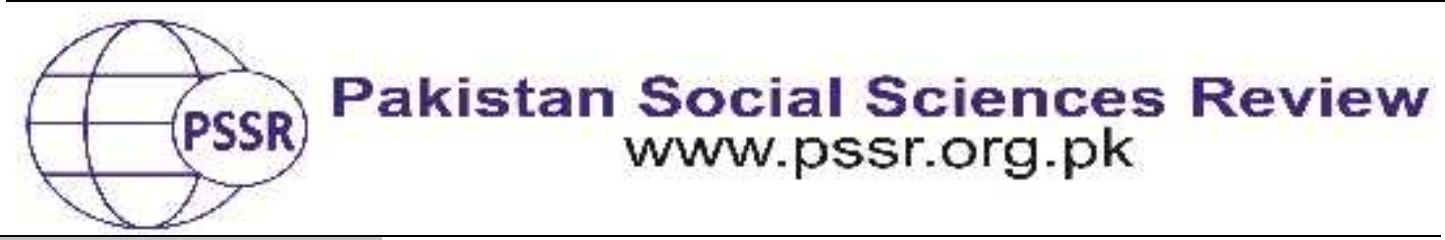

RESEARCH PAPER

\title{
The Impact of Farmland Conversion on Agricultural Production of Tehsil Takht Bhai, Khyber Pakhtunkhwa, Pakistan (1985-2015)
}

\author{
Sher Ali ${ }^{1}$ Sajjad Ali $^{2}$ Shabana Parveen ${ }^{3}$
}

1. Assistant Prof. Department of Economics, Islamia College, Peshawar, KP, Pakistan

2. Ph. D Scholar, department of Geography, University of Peshawar, KP Pakistan

3. Assistant Professor, Department of Economics, Hazara University, Mansehra, Pakistan

\begin{tabular}{|c|c|}
\hline & \\
\hline & \multirow{15}{*}{$\begin{array}{l}\text { This study is designed to observe the consequences of built } \\
\text { infrastructure on agricultural production in the tehsil Takht Bhai } \\
\text { from 1985-2015. The recent spatial techniques like Geographic } \\
\text { Information System (GIS) and Remote Sensing (RS) tools are } \\
\text { used to detect land use land cover change in the study area. The } \\
\text { satellite imageries of Lan-Sat were acquired from the open } \\
\text { source web Global Land Cover Facility (GLCF), the images } \\
\text { obtained from this source were then classified and processed in } \\
\text { ArcMap to determine a clear scenario of spatial and temporal } \\
\text { land use dynamics in the area under investigation. Moreover, } \\
\text { for the analysis of acquired data the Statistical tool, like } \\
\text { correlation is used. The analysis showed that rapid physical } \\
\text { expansion in infrastructure is reported in the area during the } \\
\text { examination period from 1985-2015. The built area is increased } \\
\text { about six times in the tehsil takht bhai during study hours, by } \\
\text { engulfing agricultural land. Therefore, it is a dire need of the } \\
\text { time for government and land use lanner to device new land use } \\
\text { policies and strategies for proper land use, and to reduce further } \\
\text { undesirable and unintentional physical expansion on } \\
\text { agricultural land. }\end{array}$} \\
\hline & \\
\hline & \\
\hline & \\
\hline & \\
\hline & \\
\hline & \\
\hline & \\
\hline & \\
\hline & \\
\hline & \\
\hline & \\
\hline & \\
\hline & \\
\hline & \\
\hline
\end{tabular}

\section{Introduction}

Pakistan belongs to one of those countries whose budget directly or indirectly depends on agriculture sector. The agriculture sector is measured the pillar of the country economy; their share was round about $46 \%$ in 1960 to the total Gross Domestic Product (GDP). The share of agriculture was condensed to $21 \%$ in 2005, though it is thought to further shrink to $19 \%$ by the end of 2017 (World Bank, 2017). This primary economic activity directly or indirectly engaged maximum number of inhabitants of the country. In 1950-51 out of the total $66 \%$ of the labor force were involved in this sector, with the passage of time, in 2003 their share was condensed to $42 \%$ and in 2010 it is further reduced to 31 percent (FAO, 2014). This intentional 
drop in contribution of the sector to the GDP and loss of employment prospects is the result of unplanned and uncontrolled expansion of built environment. This conversion of cultivated land to built-up area is the main reasons of reduction in the share of agriculture contribution to GDP (Ali, 2013). In this modern era industrialization is also one of the factors leading to migration from rural to urban areas. Pakistan belongs to one of the least economic developed countries where cultivated land is reduced due to high population growth rate, the country ranks $6^{\text {th }}$ in their growth rate more than $2 \%$ by the end of 2017. In order to satisfy the requirements of this huge number of inhabitants the available cultivated land is challenged to provide sufficient food stuff. The term high population growth rate replicates the addition of bulk of new inhabitants per year in the locality. To gratify the demands of newly added inhabitants, put further pressure on the existing territory in the form of new physical infrastructures and buildings in the globe (Ali et al., 2013). The newly creation of infrastructures and buildings on the land previously utilized for other purpose is recognized as built environment.

The loss of cultivated land and green belts (loss of grasses and trees), open spaces and barren land on the cost of built area is a common practiced reported in different regions of the world (Fischel 1982; Miller and Werner, 2018). It is predicted that, in between 2000-2050 million hectares of farmland, open spaces, environmentally sensitive land to be eaten up by physical infrastructures in United State of America (Burchell et al. 2005). Therefore, in the nearby future there will be a tough test in between the cultivated land physical expansion and the existing land will be not enough to deliver reasonable quantity of diet to overpopulated world (Zhang, 2007). This means that the present foodstuff will be deficient to gratify the nourishing demands of population in the less economic developed world (FAO, 2014). By using the modern spatial tools for temporal analysis, a common man will get a clear clue about land use transformation and their worst impacts with time (Sudhaira et al. 2004). This will also deliver a meaningful info to investigators concerned in land use land cover modification in the world (Nasreen, 2000). In premature time before industrial revolution, the information about the land use change were once acquired from different aerial photographs, topo sheets, historical records and directories, in that time these sources were only means of information, due to their complex nature it was difficult in understanding as well as also time consuming process and out of the reach of a common man (Han et al. 2008). In recent era the high spatial resolution imageries offers suitable data to land use scientist and researchers, in a direction to perceive land use dynamics in different region of the world (Rahman, 2007). In the developed world like United States of America (USA), it is predicted that during the time period from 2000-2025 million hectares of farmland, environmentally complex land, open spaces and barren land taken up by built-up area (Burchell et al. 2005). Furthermore, in other developed world such as Japan, Taiwan and South Korea the cropland was lost by the rapid increase in their population, in the era before industrialization in the beginning of eighteen century (Heimlich, 1989). In this regard, the country Japan has out-of-place 5.2\% of cropland in the investigation period during 1970 to 1995, while the South Korea eats 4.6\% of 
cultivated land by engulfing by the built-up area during examination era from 1965 to 1995. In the similar way, the Taiwan has also lost $4.2 \%$ of its farmland on the cost of new built-up environment in a study time of 1962 to 1994 . According to an investigation carried out by Schulze in (2010) by using CORINE1 satellite imageries, determined that the physical expansion in built environment engulfed 74,393 hectares of cropland, green belts, and open spaces in Germany, while, in United Kingdom (UK) 20,397 hectares of farmland was eaten by built-up area in a time period of 1960-2000. This reflects that the rate of engulfing of cultivated area in Germany is several times more than that of reported from the UK (Schulze, 2010).

In developing world like Bangladesh, the expansion in built environment has badly encroached cultivated in their urban and urban fringe (Quasem, 2011). This land use transformation is the result of the creation of new buildings for shelter, educational institute, health centers, Parks, playgrounds, roads and a variety of shopping centers. Similarly, in India the establishment of new industrial set up is on pure agricultural land and other infrastructure in the shape of different housing societies, educational and vocational institutes, health and professional centers, land for business activities and play grounds consumed the productive cropland in the country (Fazal, 2000). In the similar pattern in the Hochi Minh urban center of Vietnam maximum level of the fertile farmland was infringed by physical constructions (Van, 2006). Moreover, in the country of Nigeria the cultivated land was badly affected by physical expansion and the rate of loss of cropland was more accelerated (Eko et al. 2012). In China from 1965 to 1994, $10.6 \%$ of cropland was declined though, 5.9 million of people were further added to the population in this said era, means 0.19 million of inhabitants were adding per year in to then population of the country during study period of thirty years from 1965-1994 (Brown, 1995; Lugo, 1996; Zhang et al. 2007). The current land use dynamics caused in lessening of agronomic land and woodland cover, and credited to numerous threats like desertification, soil erosion and salinity in United States of America (Jan, 2013). Similarly, the land use modification badly affects the quality of air, loss of habitat for birds and animals, degradation of environment and accelerated the pace natural hazards like floods and deforestation and desertification in Nanital, India (Prakash, 2008).

Moreover, dynamics in land use pattern in Pakistan is due to rapid increase in population, high ratio of urbanization, the high land values and advents of modern industrialization. Like other third world countries, Pakistan is likewise the target of urban challenges due to their uncontrolled population growth rate. The entire people residing in the country were 173.5 million. Out of the total the 67.1 million inhabitants were reported from urban centers, having the 140 persons per square kilometer density in the year of 1990, the density of population enhanced to 225.2 persons per square kilometer in 2010 in the country (Yar, 2013). This high population growth rate is the crucial aspect accountable for numerous problems like agricultural land alteration, road traffic overcrowding, ecological contamination, deficiency of houses, lack of electricity, absence of land use strategies, shortage of 
water and water pollution (Qadeer, 1996). The land use modification in the metropolises of Pakistan is swelling very quickly, as related to other unindustrialized states of the world due to unusual increase in the inhabitants and socio-economic growth (Yar, 2013). On the time of partition, the total number of dwellers was 33 million rose to 43 million in 1961, the number of people doubled to 86 million in the census carried out in1972 in the country. Further, the figure rose to 131 million in the census of 1998 (Abu- Laghod, 1991). According to the census report of 1998, the 43 million of inhabitants were living in the urban centers, with the growth rate of $3.06 \%$ per annum. While, the growth rate of rural population was $2.05 \%$ per annum (FAO, 2014). Due to this rapid growth rate, the projected inhabitants of the country are 260 million by the end of 2030, and it is further forecasted that out of whole resident half of the inhabitants $50 \%$ would be residing in urban centers, while the rest of people will be in the rural community of the country.

This rise in urban inhabitants will be accountable for the loss of ecological land the arable land, soil, water and air contamination (Murtaza \& Irteza, 2006). In the absence of appropriate government strategies and suitable planning, farming land, culturable waste land and other entertaining hubs are transformed into physical constructions (Barney, 2006). In the city of Lahore, the exponential increase in urban people credited to the loss of most of the cultivated land by the encroachment of urban center (Jamal et al. 2012). In the similar pattern in the Faisalabad district due to explosive population growth rate caused in expansion of new physical infrastructures and henceforth surge city area folded two time from 102 to 213 sq. $\mathrm{km}$ in a duration from 1980-2010 (Bhalli et al. 2012). In the province of Khyber Pakhtunkhwa (KP), the total number of urban centers were 28 in the year 1962, with the passage of time due to natural increase and rural to urban migration the number of urban centers rose to 55 in 1998, it shows that the number of city centers nearby doubled in only 36 years in the province (Raman, 2007). This increase in the number of urban areas reduced badly the agrarian land in the KP, in Mardan district 1125 hectares of cultivated land has been converted in to other land use due to lack of proper land use policies in a time period of only 20 years from 1990 to 2010 (Yar, 2013). Therefore, cropland extension is required in a directive to achieve the basic requirements of the rising population, as each year thousands of hectares of fertile cropland is lost as a result of urban expansion in the country (Bradshaw and Muller, 1998). In response of rigid and strict land use policies the local government of America condensed 13\% of built-up area in Washington, $12.6 \%$ in Oregon, in California and Nevada the $9.5 \%$ and $2.8 \%$ in only 15 years of period from 1982 to 1997 (Zubair, 2006). The similar policies are essential in Pakistan to be practiced very strictly, as there is a limited cropland in comparison to its population and the per person availability of cultivated land is decreasing rapidly (Khan and Hye, 2010). In the time of independence in 1947, per capita cultivated area was 0.4 hectare, reduced to smaller than 0.1 hectare in 2009 (Nasreen, 2000). So, therefore it is needed to reserve and save each and every inch of land from further conversion by implementing strict land use policies in Pakistan. To lessen the causative forces leading to physical expansion on the cost of agrarian land encroachment will 
support to reduce the issue of cropland conversion to physical infrastructure (Nunes and Auge, 1999).

\section{Tehsil Takht Bhai}

Tehsil Takht Bhai is one of the administrative units of district Mardan. District Mardan is divided in to three administrative unit tehsils namely Tehsil Mardan, Takht bhai and Katlang. This tehsil lies in the fertile valley of Peshawar (Figure 1). Tehsil takht bhai is the second most populous tehsil after the Mardan tehsil. The total land area of the Tehsil Takht Bhai is about $414 \mathrm{sq} . \mathrm{km}$ and the home of about 402,706 population in the census of 1998, and the density of the population was 972 people per square kilometer (GOP, 1999).

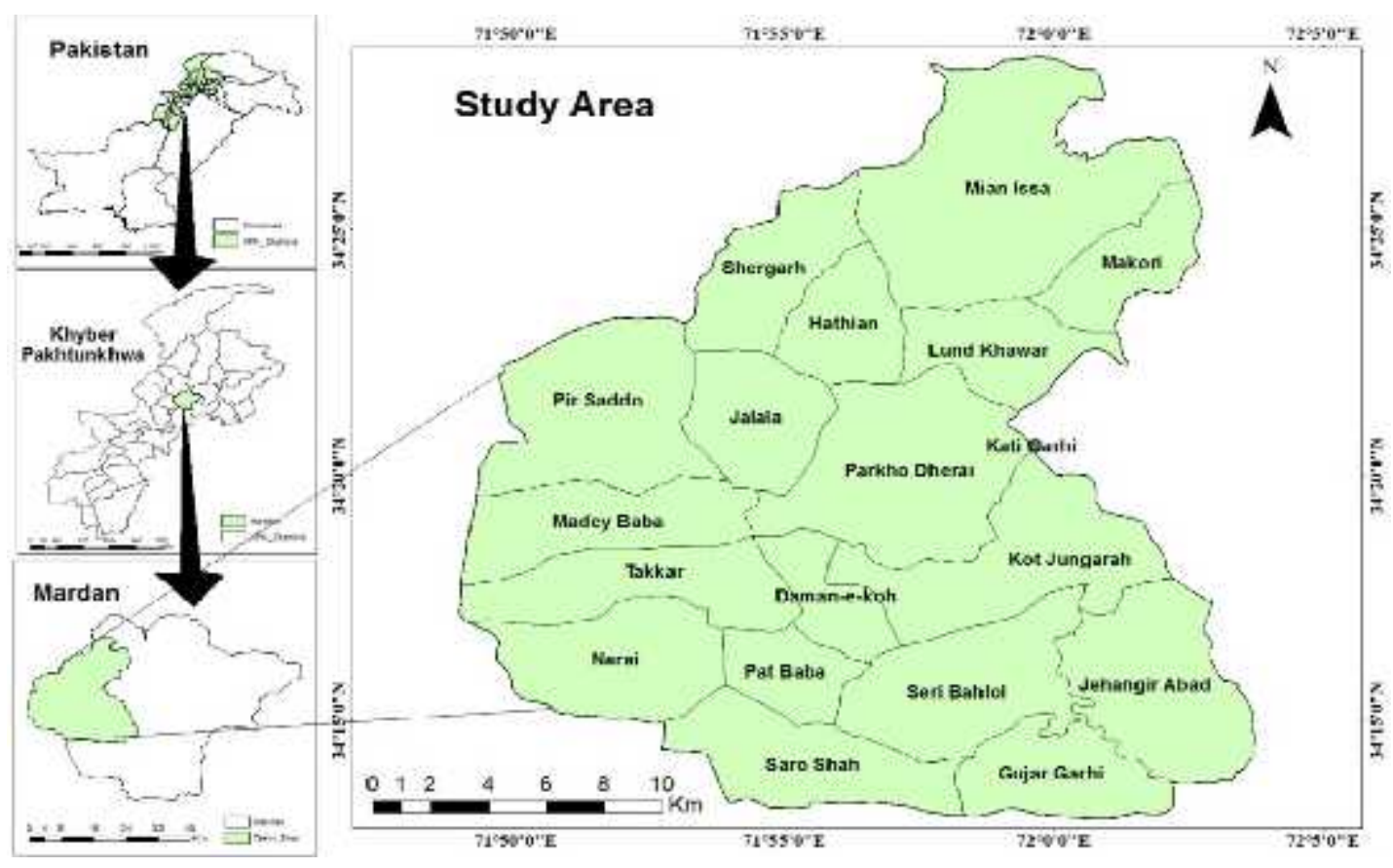

Figure-1: Location of the Tehsil Takht Bhai, District Mardan

According to the 1981 population census report, the population of Tehsil was figured 218,026, increased to 402,706 in the next census carried out in 1998 (GOP, 1999) (Table 1). The number of inhabitants were increasing with a growth rate of $3.06 \%$ per year in the study area, while the growth rate of the tehsil was $3.1 \%$ per anum during population census of 1972 to 1981 (GOP, 1983). During the soviet war in 1979, thousands of Afghani refugees came to the area and settled there in various parts of the Tehsil and district. This further increase in the number of people placed marvelous pressure on agricultural land, and the portion of agricultural land has badly reduced and the availability of per capita farmland reduced to dreadful level. This decrease in the cultivated area due to increase in the number of inhabitants led to a condition in which the existing land is not enough to gratify the food 
requirements of their inhabitants living in, and the land further pressured to satisfy the shelter demand as well.

Table 1

Tehsil Takht Bhai's Population and Population Density 1951-2017

\begin{tabular}{ccccc}
\hline Years & Population & $\begin{array}{c}\text { Change in } \\
\text { Population }\end{array}$ & $\begin{array}{c}\text { Population } \\
\text { Density }\end{array}$ & Growth Rate \\
\hline 1951 & 25,414 & $\ldots \ldots \ldots$ & 61 & $\ldots \ldots$. \\
\hline 1961 & 51,455 & 26041 & 124 & 3.03 \\
\hline 1972 & 87,790 & 36335 & 212 & 3.23 \\
\hline 1981 & 218,026 & 130,236 & 526 & 2.81 \\
\hline 1998 & 402,706 & 184,680 & 972 & 3.01 \\
\hline 2015 & 664,223 & 261,517 & 1604 & 2.65 \\
\hline 2017 & 803.108 & 278,172 & 1708 & 2.01 \\
\hline \multicolumn{5}{c}{ Source: Government of Pakistan, various issues } \\
\end{tabular}

The expansion in built area in the tehsil led to enhance the land value of per Marla plots. The data about land value was acquired by designing questionnaire survey in the following union councils for patwaris and property dealers of the tehsil. In this survey the land values are showed in (000) of Pakistani rupees (Table2 ). The investigation exposed that the land values in the area increased so many times during the study period. The maximum per Marla terrestrial value is recorded in Chail union council of tehsil takht bhai, having per Marla of Commercial land is in between 70,000 to 120,000 and cultivated area is in the range of 25,000 to 40,000 in 1990. Gradually with the passage of time the land value increases, and the figure rose to 150,000-300,000 per Marla of commercial plot in 2016. and the value of per Marla agricultural land range in between 80,000 to 120,000 .

Table 2

Tehsil Takht Bhai, Land Values Per Marla, 2000-2016

\begin{tabular}{|c|c|c|c|c|}
\hline \multirow{2}{*}{$\begin{array}{c}\text { Sample } \\
\text { Villages }\end{array}$} & \multicolumn{2}{|c|}{$\begin{array}{c}\text { Land Value in PKR (000) } \\
2000\end{array}$} & \multicolumn{2}{|c|}{ Land Value in PKR (000) 2016} \\
\hline & Agricultural & Commercial & Agricultural & Commercial \\
\hline Lund Khwar & $15-25$ & $70-100$ & $50-80$ & $150-230$ \\
\hline Qutab Garh & $20-40$ & $70-120$ & $40-70$ & $120-200$ \\
\hline Parkho Deri & $15-30$ & $60-100$ & $40-90$ & $120-230$ \\
\hline Shabat Khel & $20-50$ & $60-100$ & $50-80$ & $150-250$ \\
\hline Saro Shah & $30-50$ & $80-130$ & $60-100$ & $120-220$ \\
\hline Chail & $25-40$ & $70-120$ & $80-120$ & $150-300$ \\
\hline Ahmad Abad & $35-60$ & $80-120$ & $70-120$ & $140-280$ \\
\hline
\end{tabular}

Source: Survey of Revenue Officials and Property Dealers, 2017 


\section{Materials and Methods}

\section{Data Source}

For this study both the primary as well as secondary data sources are consulted. Primary data were collected through questionnaire, which is designed to find out the land value. The questionnaire designed was filled from the revenue officials (Patwaris) and property dealers of the respective union council to collect union council wise temporal data for (1985-2015) the data about other parameter also acquired through this source are pattern of land utilization, various crops grown in the union councils and production of these crops for the whole tehsil. In this way, 200 questionnaires were likewise filled randomly in the various union councils shown in previous part of the paper. This procedure was operated to attain the data about differences in the values of land, area under main crops (wheat, maize, sugarcane and tobacco) and their respective production was assimilated during study hours from 1985-2015. In this method, the statistics data got were analyzed and represented them in the shape of maps, tables and geometrical charts. Due to the non-availability of the under-cropped area and crops production data of the tehsil takht bhai from 1985 the data about crops area and production is used from 1990 to 2016.

In the same way, the secondary data needed for this study were collected from different sources. The imageries of the area were downloaded from the Global Land Cover Facility (GLCF) web. The data about under cropped area and their production were acquired from the office of Agriculture Bureau of Statistics Peshawar, the demographic data about the study area got from the Population Census Organization (PCO), Peshawar. The imageries of Land sat satellite for the year 1985 and 2015 acquired from Global Land Cover Facility were processed and classified in to different classes in ArcMap to perceive spatial and temporal land use modification in the area of interest.

\section{Data Analysis}

The data collected about different variables were analyzed by means of SPSS, cartographic procedures and arithmetical analysis using, Co-efficient of correlation between land use and their production in the form of major crops grown in the study area. Similarly, the satellite imageries of Land sat were processed and classified, by means of supervised and unsupervised classification mechanism in order to notice the pattern of land use dynamics in the area under observation. Finally, the investigated data were represented in the shape of different maps, tables and statistical diagrams of the desired area. 


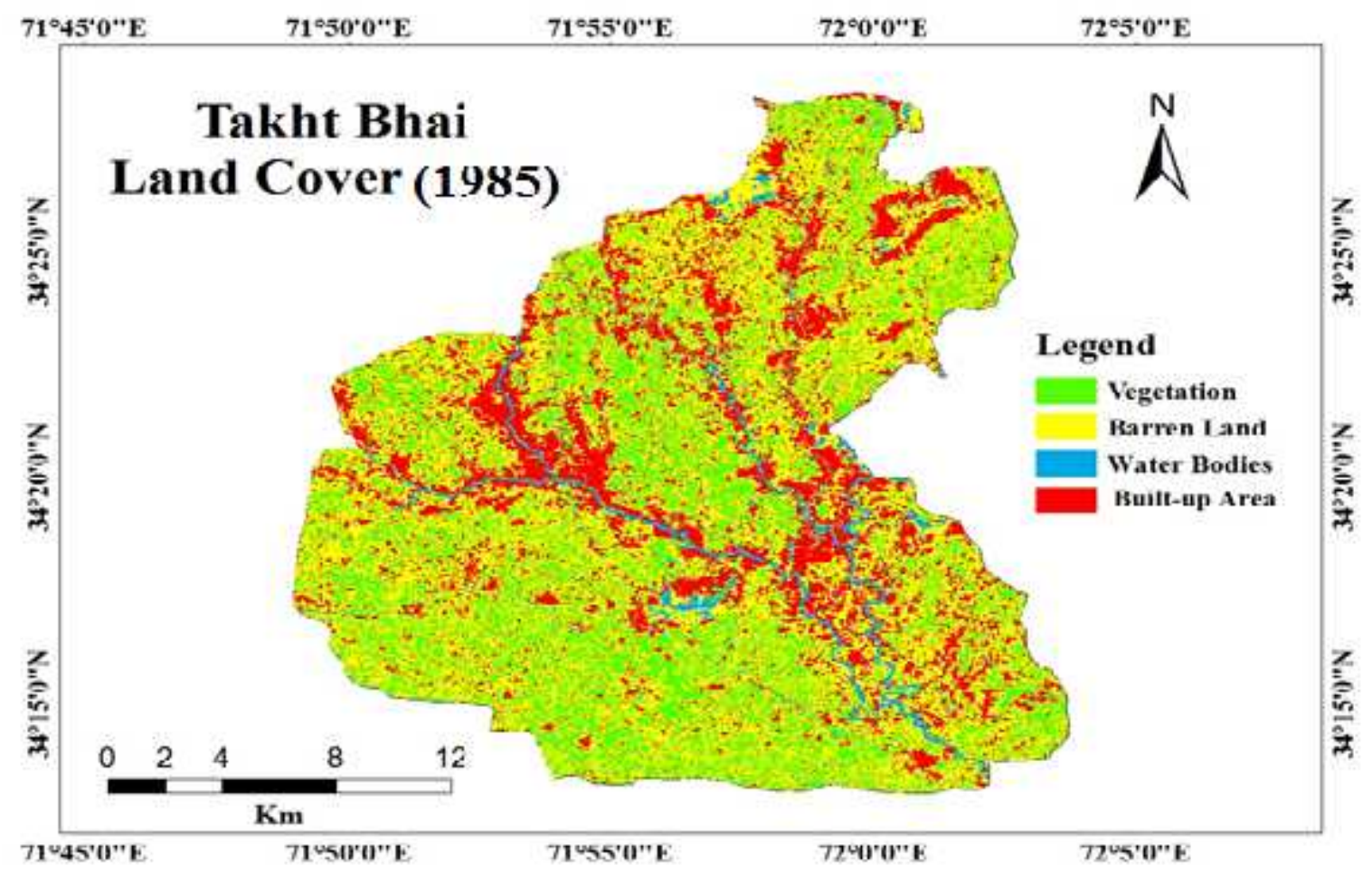

Figure.2 land use pattern of the study area, 1985.

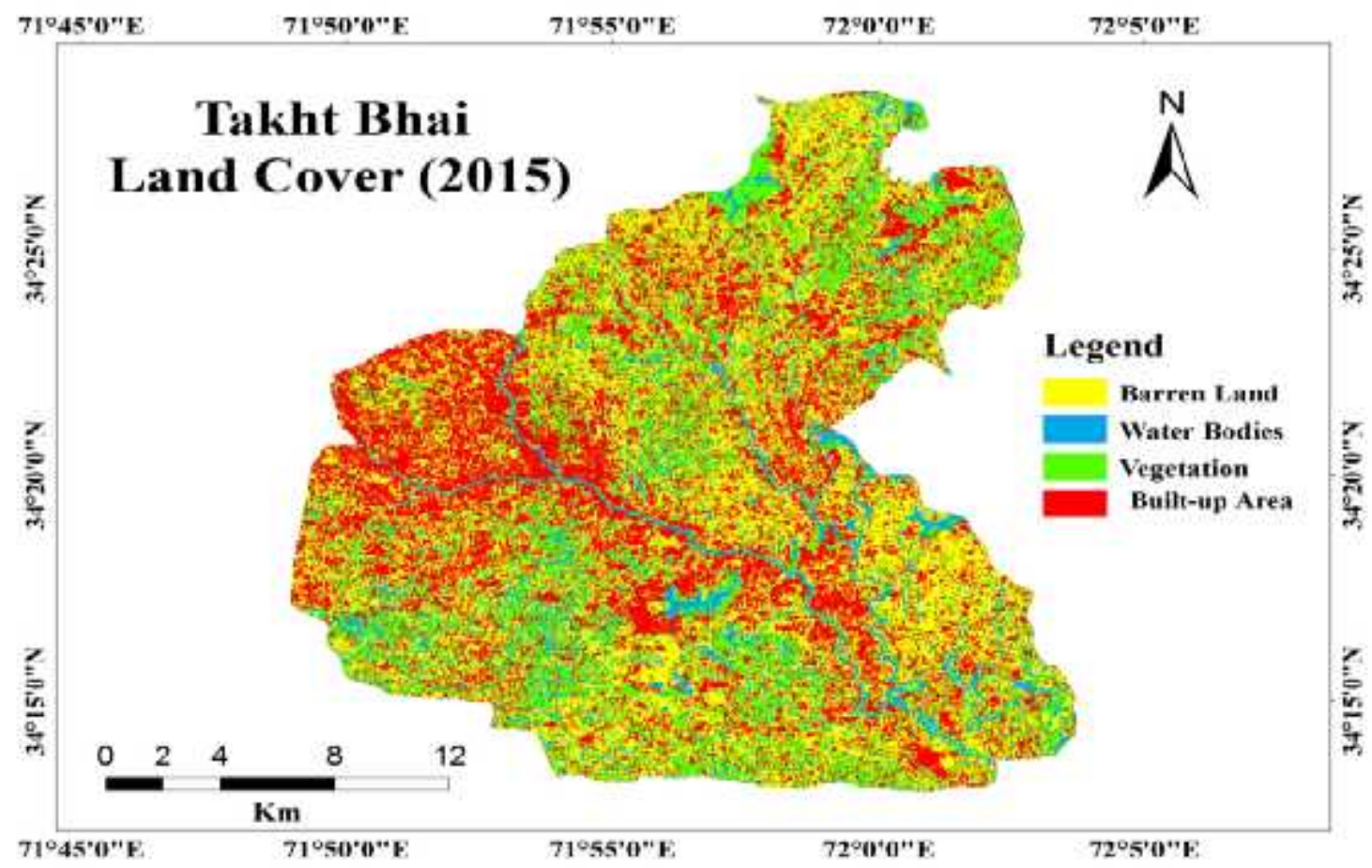

Figure.3 land use pattern of the study area, 2015. 
Table 3

Tehsil Takht Bhai comparison in Land Cover, 1985 and 2015

\begin{tabular}{cccc}
\hline Land Cover & $\begin{array}{c}\text { Area in Sq. } \mathbf{~ k m} \\
\mathbf{1 9 8 5}\end{array}$ & $\begin{array}{c}\text { Area in Sq. } \mathbf{~ k m} \\
\mathbf{2 0 1 5}\end{array}$ & $\begin{array}{c}\text { Change in area in } \\
\text { Sq.km 1985-2015 }\end{array}$ \\
\hline Vegetation Cover & 146 & 91 & -55 \\
\hline Barren Land & 157 & 143 & -4 \\
\hline Built up Area & 100 & 156 & +56 \\
\hline Water Bodies & 10 & 12 & +2 \\
\hline
\end{tabular}

Source: Land Revenue Record, 1985 and 2015

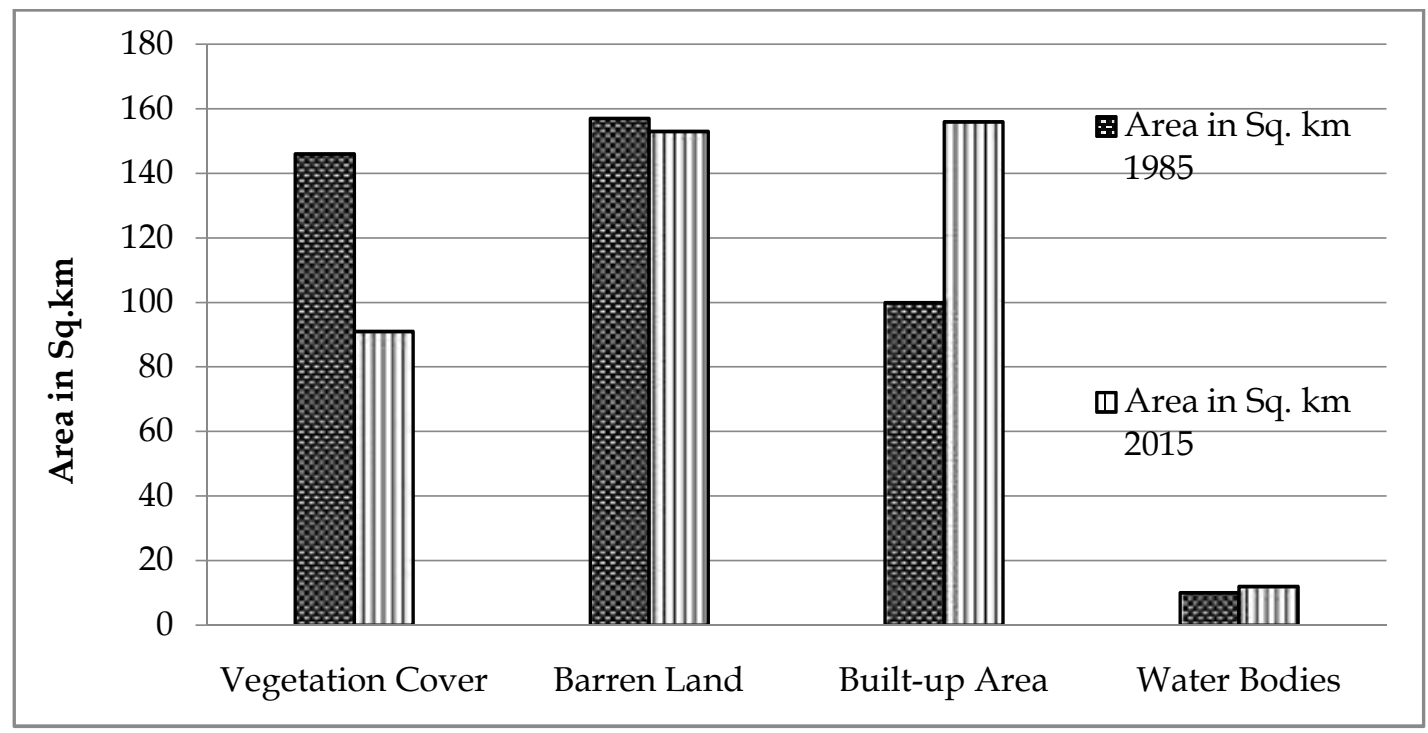

Figure- 4 Tehsil Takht Bhai comparison in Land Cover, 1985 and 2015

This is showed from the results of land use land cover dynamics that 55 Square kilometers agricultural area has been misplaced during 1985 to 2015, at the rate of 2.2 Square kilometer annually in the study area (Table 3). In the same way, the built-up area enhanced by 56 Square kilometers, at the rate of 2.3 Square kilometer per anum. This designates that the rise in physical infrastructure in investigated area is attributed to accelerated rate of population increase. The analysis further revealed that the number of inhabitants of the area was 218,026 in 1981, with the density of 526 persons per Square kilometer, which augmented to 402,706 in 1998, with the population density of 972 persons per Square kilometer, and measured population for 2015 is 664,223, with the rate of density of 1604 persons per Square kilometer in the study region. Moreover, the cultivable waste area loss 4 Square kilometer of territory during the study time from 1985 to 2015 in tehsil Takht Bhai. 


\section{Results and Discussions}

The analysis shows that the moderate negative coefficient of correlation $(-0.5)$ were exist in between the area under cropped and their respective production of the maize one of the major crops of the study area. Correspondingly, the strong positive coefficient of correlations (0.9) were detected among areas occupies and their production of wheat crop, as this crop considered the king of crops, it shows that a direct relationship is exist between area and production of the wheat crop. Moreover, the analysis revealed that slightly weak positive coefficient of correlation (0.1) present among the area and production of the sugarcane crop. The analysis further showed that a negligibly negative coefficient of correlation (-0.1) is present in between area under cropped and to their and production of tobacco crop. Additionally, a moderate negative coefficient of correlation $(-0.56)$ were detected in between cultivated land and the population of the study area. This specifies that there is an inverse relation among the population and cultivated area; it means that with the rise in population the cultivated land decreases and vice versa in the study area. So, it is cleared from this study that cultivated land has badly decreased by the enormous increase in the number of inhabitants in the area under investigation throughout the study period from 1990 to 2016.

In the study area major crops like wheat, tobacco, maize and sugarcane were studied in particulars. In main crops wheat and tobacco belongs to Rabi crops while, sugar cane and maize belongs to Kharif family. The total area cultivated and uncultivated is shown in (figure 2) in the year 1990 and 2016. the land which is fit for crops is designated as cultivated land, whereas, the area which is not suitable for cultivation like cultivable waste, water bodies, water logged and built-up area is designated as uncultivated area. The cultivated and uncultivated area is shown for the year 1990 and 2016 in the whole tehsil. The figure (2) obviously determined that more than half of the territory in every village were transformed to other land use and physical infrastructure in the form of shelter houses, educational institutes, shopping centers and health care centers during the study time period from 19902016. This alteration of cropland is attributed to marvelous increase in the number of people in the study area.

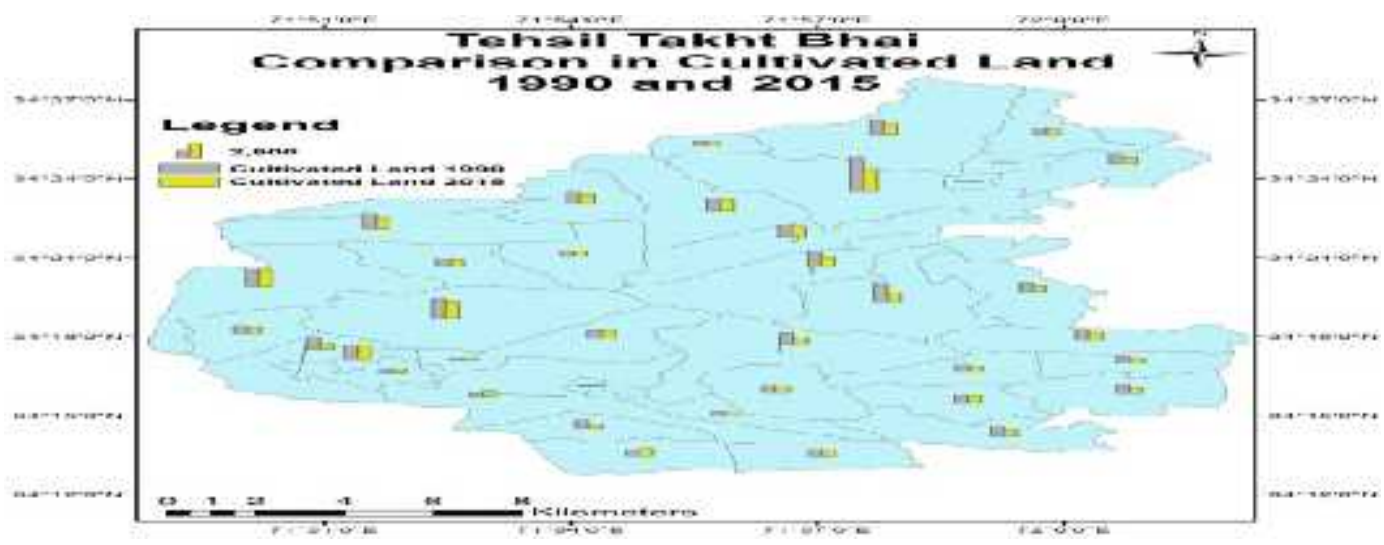


Figure-5: Tehsil takht bhai, Comparison in Cultivated Land, 1990-2016

\section{Rabi Crops}

Wheat

Wheat is the crop mainly growing best in temperate region of the world and as this crop is grown up in winter season therefore it is considered as Rabi crop. It is sowing in October and November months in the areas where rain is the only source of irrigation while, in the months of November and December in the area having canal irrigation system. Pakistan belongs to one of those countries where wheat is sowing and harvesting in both the rain feed and canal irrigated areas. It is the world foremost important crop and Globally, the production of this crop was 583 million tons in the year 2000-2001 (Gill, 2008). The main crops that is cultivated in the study area and their respective Production in tons. Similarly, the under-cropped area in hectares of the major crops from 1990-2016 are showed in the table (Table-3). The total area under this crop in 1990-91 was about 12,118 hectares and their production was recorded as 21,085 for the number of people in the area was 315,797. Slowly and steadily the cultivated land for wheat was decreased to 11,908 hectares, and their production rose to 25,364 tons in 1998-99. The number of inhabitants increased to 402,706 , with this rise in population the needs of grain also increased. In order to mollify the nutrition demands of growing residents the cultivated area for wheat crop was enhanced to 17,657 hectares in 2011-12 which in turn increase their production to 34,960 tons (Table-3, Appendix).

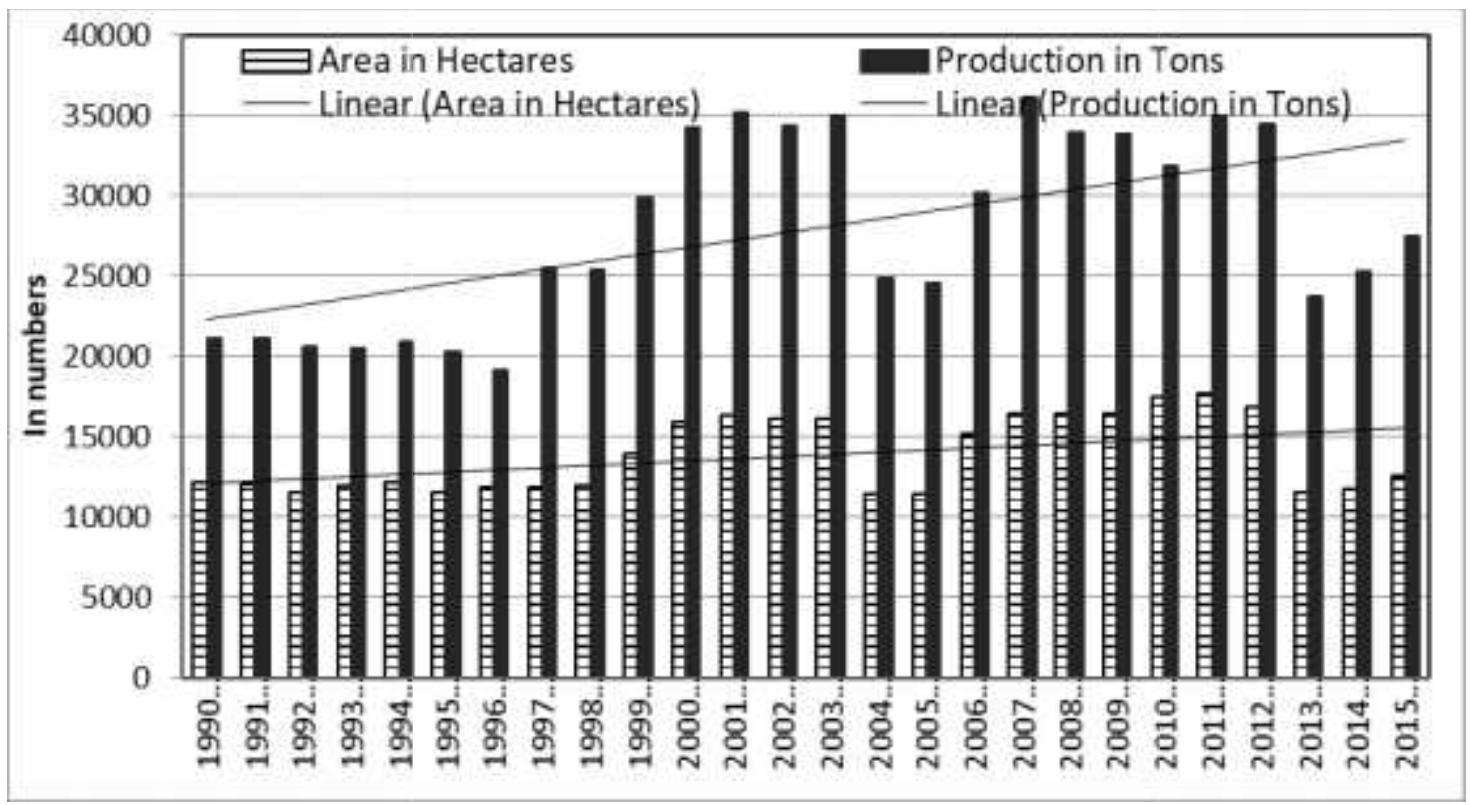

Figure-6: Tehsil Takht Bhai, Area and Production of Wheat, 1990-2016 
The study revealed that the largest share of this crop and their particular productions was reported in the year of 2007-08 in the record of the study area. Then after 2011-12 the cultivated area for the crop was shrinking due to speedy population growth. This decrease in the under-cropped area is due to the expansion in physical infrastructure on agricultural land. To satisfy the growing demands of population, the cultivated land of the wheat was restricted to 12,607 hectares in 2014-15 in tehsil Takht Bhai and delivers 27,483 tons of wheat to 664,223 of inhabitants of the tehsil takht bhai. The analysis further showed that the cropped area and their production line displayed increasing order throughout the study period from 1990 to 2016. Moreover, the analysis revealed that the yield per hectares was 1.63 tons rose to 2.16 tons per hectares in 2014-15 from 1990-91 this showed that the rate of production is in increased order in the study area. But the per capita production share is decreasing; the rate of decrease is from 66 kilogram in 1990-91 per head to 41 kilogram in 2016.

\section{Tobacco Crop}

Tobacco crop is in the category of industrial crop. This crop also designated as cash crop, cultivated in a variety of section of the biosphere. Tobacco ranks second in the major crops grown in the country, next to sugarcane. The tobacco is primarily grown in wintertime in Pakistan and therefore, denoted as Rabi crop. It is mostly grown in the November and December months in nurseries and when grow to a specific height, then it is shifted to fields from January to the end of March in the country (Jan, 2013). Once the bush grasp to maturity the color of their leaf's changes from greenish to pale yellow this is considered the crucial time of their harvesting. The leaves of this crop were then transferred for further processing to tobacco companies. The leaves of tobacco are used for the manufacturing of snuffs, cigarettes and hukkah. The range of temperature in which the tobacco crop nourished healthy is among $13-37 \mathrm{C}^{0}$ (Jan, 2013).

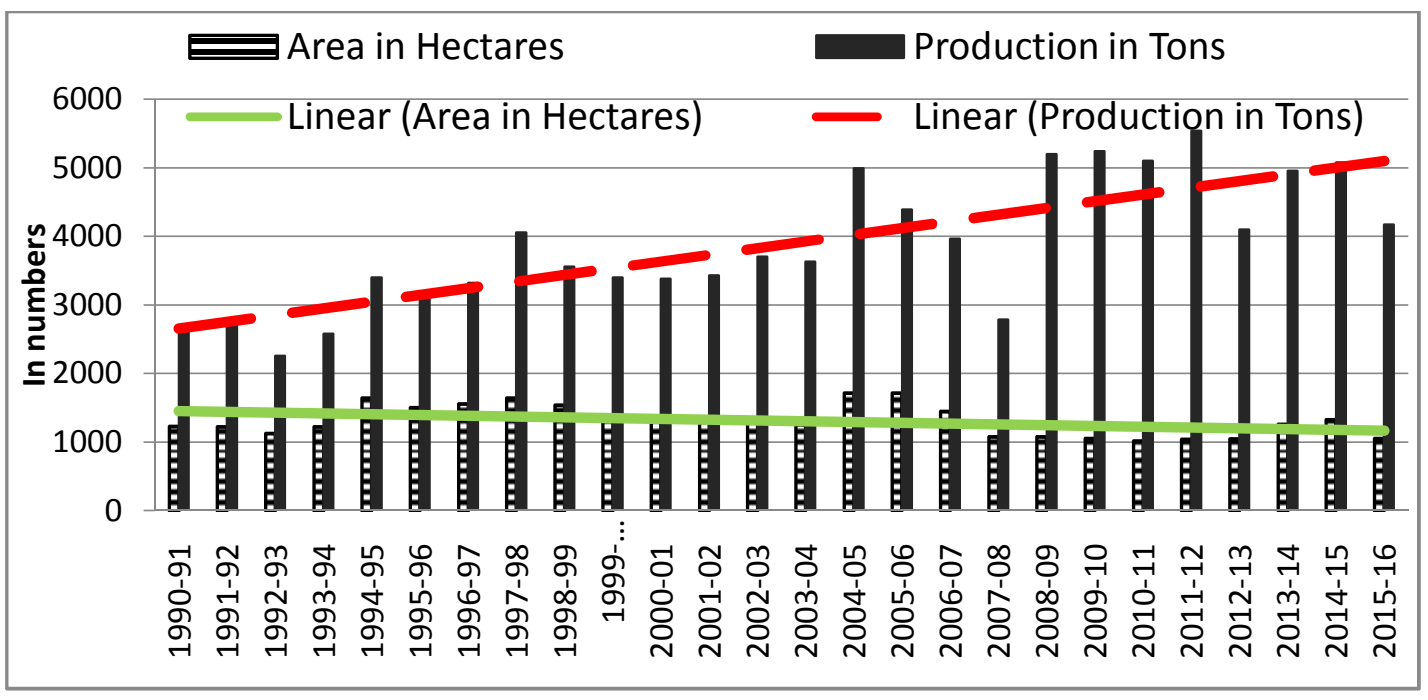




\section{Figure-7: Tehsil Takht Bhai, Area and Production of Tobacco, 1990-2016}

In the study area the cultivated area for major crops in hectares and their respective productions in tons during the study period from 1990-91 to 2014-15 is shown in (Figure 7). The analysis showed that the land area occupied by tobacco was 1231 hectares in 1990-91 and the rate of production was 2695 tons. Progressively, the cultivated area of tobacco was enhanced to 1641 hectares and production level increased to 4053 tons in the fiscal year 1997-98. With the rapid increase in the inhabitants the area for the crop was reduced to 1,016 hectares, which ultimately lessen the production to 5,100 tons in the fiscal year 2010-11 in the tehsil.

The decrease in the area is attributed to expansion in physical infrastructure to satisfy the necessities of rising population. the analysis showed that after 2011the land for this crop reduced to 1,326 hectares in tehsil, and delivers 5,078 tons of tobacco in the year of 2014-15. The analysis further showed that the land loss by tobacco crop is 177 hectares in the study period from 1990 to 2015 (Table-4, Appendix).

Moreover, the data showed that the yield per hectares of tobacco was increased from 2.17 tons per in 1990 to 3.89 tons per hectare in 2014-15. Though, per capita production share was reduced from 8 kilograms in 1990 to 6 kilograms 201415 in the tehsil Takht Bhai.

\section{Kharif Crops}

\section{Maize crop}

Maize is also recognized as corn, and in the neighborhood, it is famous on the name of Makkai. The maize is belonging to summer (kharif) crop, and mostly grown in the tropical and subtropical section of the world, having high temperature at all. The total area acquired by this crop in hectares and their production in tons in tehsil Takht Bhai throughout 1991-2016 (Table-5, Appendix).

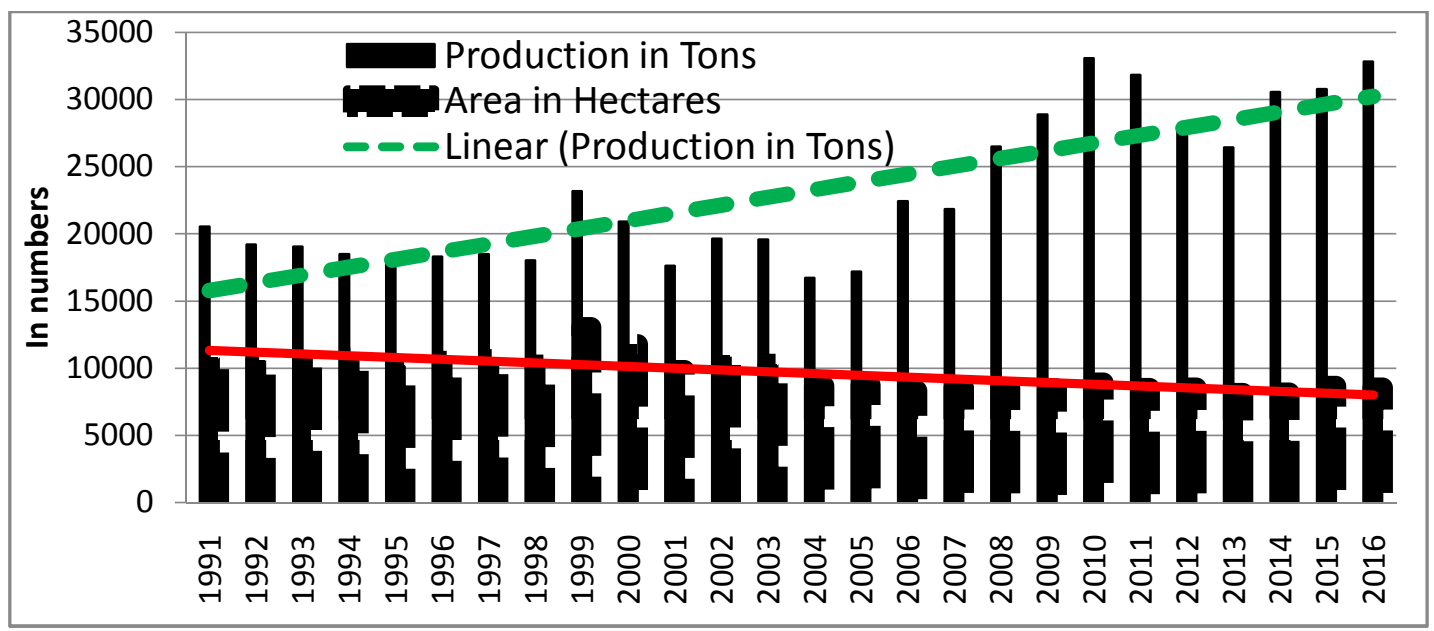




\section{Figure-8: Tehsil Takht Bhai, Area and Production of Maize, 1990-2016}

The analysis discloses that in 1991, the area under maize crop was 10,816 hectares and delivers 20,550 tons of corn to the area under study. Slowly and gradually, the occupied area under maize crop rises and reached to 13,025 hectares and producing 23,184 tons of maize grain in 1999. The results further show that after 1999 onward the occupied area under maize was decreased to 8,530 hectares and their production augmented to 32,841 tons of corn 2010. Moreover, the results declare that the total area loss by maize crops is 2,286 hectares in the study duration.

The analysis further reveals that the area under maize showed a decreasing pattern, while the production curve designates growing pattern credited to increase in the yield. The results further indicate that the rate of yield in tons per hectares was enhanced from 1.78 to 3.58 tons per hectares from 1991 to 2016 in the tehsil takht bhai, as a result of recent modern farming techniques used in the study area. Though, overall production was enhanced but the share of per capita production of maize was declined from 65 to 49 kilogram in 1991 and in 2016. The per capita declining is the result of rapid population growth rate in tehsil takht bhai. In the same pattern, the time line graph specifies, that the pattern of maize crop showing a dropping pattern, whereas the production line showing an increasing pattern throughout the investigation periods from 1991 to 2016 in the tehsil Takht Bhai of the district Mardan.

\section{Sugarcane}

Sugarcane belongs to the family of industrial crops and also known as cash crop. Next to cotton, sugarcane is considered the most significant cash crop in Pakistan. The data acquired revealed that the total area under sugarcane was 10,067 hectares in 1990-91, and the production reported from this area was 3,976 hundred tons. Consequently, the cultivated area for sugarcane increased to 10,405 hectares, and the production recorded for that area was 5,038 hundred tons in 2001-02. Furthermore, the years after 2001-02 onward the area under this crop was decreased to 9430 hectares and reported production reported in the year was 4,385 hundred tons in 2015-16 (Table-6 appendix).

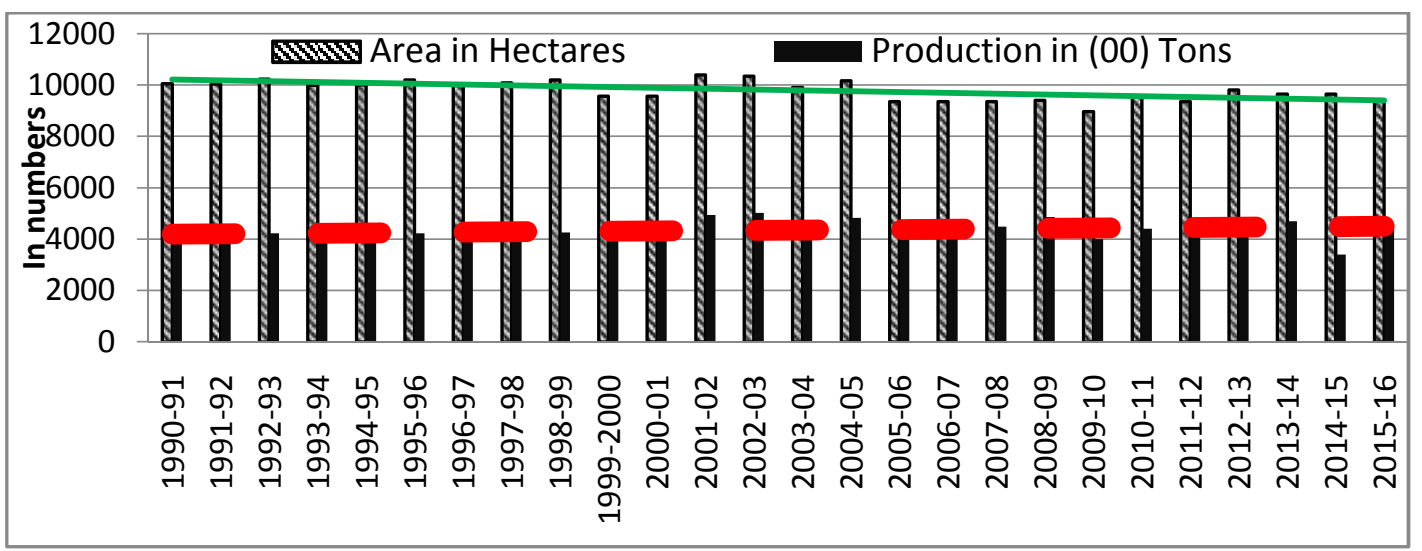




\section{Figure-9: Tehsil Takht Bhai, Area and Production of Sugarcane, 1990-2016}

The results reveal that the area loss by this crop is 637 hectares in the study duration from 1990-2016 in tehsil takht bhai. The analysis further indicates that both the cultivated area and their production curve line is an irregular order of increasing and decreasing outline. In the same pattern, the per hectare yield in 1990-91 was 39.5 hundred tons, augmented to 46.78 hundred tons per hectare in 2015-16, this resulted an increase in overall production many folds in the tehsil Takht Bhai. Whereas, the per head yield part is declined from 1259 to 660 kilogram of sugarcane from 1990-91 to 2015-16 is resulting due to rising in the number of inhabitants in tehsil Takht Bhai.

In the similar pattern, the statistical results of coefficient of correlation among the total cultivated area of sugar cane crop and their production indicates that there exist (-0.5) a negative correlation these two variables in the study area. This indicates that if the number population raising the under-cropped area for the sugarcane crop would be decreasing and vice versa.

\section{Conclusion}

The analysis of the study area reveals that the cultivated area is incessantly submerging by built-up area during the investigation period from 1985 to 2015 . The results further reveal that the territory under wheat crop in 1990-91 was 12,118 hectares and providing 21,085 tons of grain to the area, for the total population of 315,797 , with the rate of production of 1.63 tons of grains. This shows that in the fiscal year 1990-91 the per capita production reported was 66 kilograms, whereas, in 2015-16 the area under this crop decreased to 12,607 hectares, providing 27,483 tons of grain to 664,223 number of inhabitants, at the rate of 2.16 tons per hectare. This further showed that out of the total per capita share is decreased to 41 kilogram of wheat in 2016. In the similar way, the land occupied by the tobacco, sugarcane and maize crop in 1990-91 was 1,231, 10,816 and 10,067 hectares respectively and their respective output was 2,695, 20,550 and 3976 hundred tons, with the per hectare rate of 2.17, 1.78 and 39.5 tons. The results further revealed, that in 2014-15, the area under tobacco, maize and sugarcane was 1,326, 9430 and 8530 hectares, and their respective production for the fiscal year 2015-16 reported was 5078, 32841 and 4385 hundred tons. The per hectare production rate for tobacco, maize and sugar cane crops was 3.89, 3.58 and 46.78 tons in 2015-16 respectively. This is clear from the results that in 1990-91 the sugarcane and maize provide 1259 and 65 kilograms of sugarcane and corn per head. While, 2015-16 the per head share of sugarcane and maize was reduced to 660 and 49 kilogram due to the rising population growth rate in the study area. This indicates that the production of major crops per hectare was showing an increasing trend but the per person share of the major crops showing a decreasing pattern of growth in the study period in the tehsil takht bhai.

In the same way the statistical analysis is used in the form of simple coefficient of correlation among under cropped area of major crops and their production. The results indicate, that the moderate negative coefficient of correlation 
$(-0.5)$ exist in between cultivated area and production of corn. Similarly, a strong positive coefficient of correlations (0.9) were found among under-cropped area and their production for grain, it replicates that there exist a direct relation in between cultivated land and production of the crop. Moreover, the analysis further reveals, that a negligibly weak positive coefficient of correlation (0.1) and negligibly negative $(-0.1)$ are found among the cropped area and their respective production of the sugar and tobacco crop. The analysis further showed that a moderate negative coefficient of correlation $(-0.56)$ is exist in between the total cultivated land and number of people residing in the tehsil takht bhai from 1990 to 2016. This result of correlation specifies that the number of increases in the inhabitants is inversely proportional to the total under-cropped area of the tehsil. 


\section{References}

Abu-Laghod, J. (1991). Urban Sociology. New York, Harper Collins.

Ali, S. (2013). An Analysis of the Impact of Globalization on Macroeconomics Performance in Pakistan. Thesis submitted to the Department of Economics Gomal University, D.I. Khan, Pakistan.

Ali, S., Amin, A. \& Ali, A. (2013). The Impact of Population Growth on Economic Development in Pakistan. Middle East Journal of Scientific Research, 18(4): 483493.2013.

Barney, C. (2006). Urbanization in Developing Countries: current trends, Future projection, and key Challenges for Sustainability. Technology in Society, 28(1):6380 .

Bhalli, M. N. Ghaffar, A. \& Shiraz, S.A. (2012). Remote Sensing and GIS Applications for Monitioring and Assessment of the Urban Sprawl in Faisalabad- Pakistan. Pakistan Journal of Science, 63(3):212-237.

Bradshaw, T.K; Muller, B. (1998). Impacts of rapid urban growth on farmland conversion: Application of new regional Land use policy models and geographical information systems. Rural sociology, 63(1):1-5.

Brown, L.R. (1995). Who Will Feed China? W.W Norton and Company, New York

Burchell, R. Downs, A. McCann, B \& Mukherjee, S. (2005). Growth costs: Economic impacts of unchecked development. Island Press.

Eko, A.J; Offiong, R.A; Eni, D.I; Esien, O.E. (2012). The Effects of Urban Sprawl on peripheral Agricultural Lands in Calabar, Nigeria. International Review of Social Sciences and Humanities 2(2):68-76.

Fazal, S. (2000). Urban expansion and loss of agricultural land. A GIS based study of Saharanpur City, India. Environment and Urbanization, 12 (2):123-157.

Food and agriculture organization, (2014). Globalization of Food System in Developing Countries: impact on Food Security and Nutrition, Food and Nutrition Paper, 83, Rome, Food and agriculture organization.

Fischel, W.A. (1982). The Economics of Zoning Laws: A property Right Approach to American land use Controls. Baltimore: The John Hopkins University press.

Gill, J. (2008). The Effect of Urban Sprawl on Peri-Urban Agricultural Region. Applied Geography, 30 (3): 370-379. 
Han, S.S. Li, H.T. \& Gu, H.Y. (2008). The Study of Land Use Change Detection Based on Object-Oriented Analysis. International Workshop on Earth Observation and Remote Sensing Applications: 1-6.

Heimlich, R.E. (1989). Metropolitan agriculture: Farming in the city's shadow. Journal of the American Planning Association, 55(4), 457-466.

Jamal, S.B. Wadood, A. Ghufran, M. Naeem, M. Khan, A. \& Ghaffar, R. (2012). Phytochemical analysis of medicinal plants occurring in local area of Mardan. Biochem Anal Biochem, 2(4), 1-4

Jan, A. (2013). Cropping Technology. Karachi. Oxford university press.

Khan, F. K. (2001). Geography of Pakistan. Karachi. Oxford university press.

Khan, F. K. (2005). Geography of Pakistan. Karachi. Oxford university press.

Khan, R.E.A. \& Hye, Q.M.A. (2010). Financial sector reforms and household savings in Pakistan: An ARDL approach. African Journal of Business Management, 4 (16):3447-3456.

Lugo, A. E \& Scatena, F.N. (1996). Background and catastrophic tree mortality in tropical moist, wet, and rain forests. Biotropica, 585-599.

Miller, R.W. Hauer, R.J. \& Werner, L.P. (2018). Urban forestry: planning and managing urban green spaces. International Journal of Remote Sensing, 7 (1): 3-17.

Murtaza, H. \& Irteza, H. (2006).Urban Development in Pakistan: Case Studies on Best Approaches to Sustainable Urban and Regional Development, Asian Development Bank, manila, Philippines.

Nasreen, I.K. (2000). Temporal mapping and Spatial Analysis of Land transformation due to Urbanization and Its impacts on surface water system: A case study of Dhaka Metropolitan area, Bangladesh.

Nunes. C. \& Auge, J.I. (1999). Land use and land cover change: implementation Strategy. IGBP report 48, International Human development program (IHDP) report 10.

Prakash, T. (2008). Land Use Changes in Himalaya and their Impacts on environment, Society and Economy: A case Study of the lake Region in Kumauni Himalaya, India. Advances in atmospheric sciences, 25 (6): 1029-1042.

Qadeer, M.A. (1996). An Assessment of Pakistan's Urban Policies, 1947-1997.The Pakistan Development Review, 31 (2): 443-465. 
Quasem, A. (2011). Conversion of Agricultural land to Nonagricultural uses in Bangladesh: Extent and determinants. Advances in atmospheric sciences 1(1):2551.

Rahman, A. \& Khan, A.N. (2007). Agricultural Land Use Change Detection in Tank and D.I.Khan Districts, NWFP. Journal Geographical Papers, 1(1): 33-50

Rahman, A. (2008). Environmental impacts of Chashma Right Bank Canal on the land use and agricultural resources of D.I.Khan District, Pakistan. PhD thesis Department of Geography, Urban \& regional Planning, University of Peshawar-Pakistan

Schulze Baing, A. (2010). Comparing brownfield reuse policies in England and Germany. International Planning Studies. 15(1): 25-35.

Schulze Baing, A. (2010). Comparing brownfield reuse policies in England and Germany. International Planning Studies. 15(1): 25-35.

Sudhira, H.S. Ramachandra, T.V. \& Jagadish, K.S. (2004). Urban sprawl: metrics, dynamics and modeling using GIS. International Journal of Applied Earth Observation and Geo information, 5(1): 29-39.

Van, T.T. (2006). Research on the Effects of Urban Expansion on Agricultural Land in Ho Chi Minh City of Vietnam by Using Remote Sensing Method. VNU Journal of Sciences, Earth Sciences 24(1):104-111.

Yar, P. Rahman, A. \& Samiullah. (2013). Spatio-temporal Analysis of Urban Expansion on Farmland and Its Impact on the Agricultural Land Use of Mardan City, Pakistan. Life and Environmental Sciences 53 (1), 35-46

Zhang, T. (2007). Community features and urban growth: the case of the Chicago metropolitan region. Land Use Policy 18.

Zhang, X. Menon, S. Denman, K.L. Brasseur, G. Chidthaisong, A, Ciais, P. Cox, P.M; \& Jacob, D. (2007). Couplings between changes in the climate system and biogeochemistry (No. LBNL-464E). Ernest Orlando Lawrence Berkeley National Laboratory, Berkeley, CA (US).

Zubair, A. (2006). Change Detection in Land Use and Land Cover using Remote Sensing data and Geographic Information System. Unpublished M.Sc. Thesis submitted to the department of Geography, University of Ibadan, Nigeria 